\title{
The Quest for the Ideal Darcy-Weisbach Friction Factor Equation from the Perspective of a Building Services Engineer
}

\author{
Bacoţiu Ciprian
}

\begin{abstract}
The calculation of the friction factor involved in the Darcy-Weisbach equation has a key role in the accurate assessment of distributed head losses. For the turbulent flow regime, this friction factor was mathematically expressed in the form of the Colebrook-White (C-W) equation, widely accepted by engineers and scientists. Nevertheless, the $\mathrm{C}-\mathrm{W}$ equation is an implicit one and must be solved using numerical methods. This is a major disadvantage for the average engineer, who always prefers an explicit equation which could be easily integrated into his familiar spreadsheet environment. The present paper is investigating some of the most used explicit alternatives to the $\mathrm{C}-\mathrm{W}$ equation, with respect to several case scenarios taken from typical Building Services hydraulic calculations.
\end{abstract}

Keywords - Colebrook-White, explicit equations, friction factor, relative errors

\section{INTRODUCTION}

Linear friction losses generated by fluid flow under pressure in closed pipes are calculated by the Darcy-Weisbach equation:

$$
h_{r}=\lambda \cdot \frac{L}{D} \cdot \frac{V^{2}}{2 \cdot g}
$$

where $h_{r}$ - distributed friction losses, in $\mathrm{m} ; \lambda$ - Darcy friction factor, dimensionless; D - internal diameter of the pipe, in $\mathrm{m} ; L$ - pipe length, in $\mathrm{m} ; V$ - average velocity across the pipe section, in $\mathrm{m} / \mathrm{s} ; g$ - gravitational acceleration, in $\mathrm{m} / \mathrm{s}^{2}$.

The key issue here is the friction factor $\lambda$, which is a function of Reynolds number, relative roughness and flow regime:

$$
\lambda=f(\operatorname{Re}, k / D)
$$

where $k / D$ - relative roughness of the pipe, dimensionless; Re - Reynolds number, dimensionless;

$$
R e=\frac{V \cdot D}{v}
$$

where $v$ - kinematic viscosity of the fluid, in $\mathrm{m}^{2} / \mathrm{s}$. 
The Colebrook-White (C-W) equation for the friction factor, published in 1939, was widely accepted by engineers and scientists as very appropriate for describing the measured data:

$$
\frac{1}{\sqrt{\lambda}}=-2 \cdot \log _{10}\left(\frac{k / D}{3.7}+\frac{2.51}{\operatorname{Re}} \cdot \frac{1}{\sqrt{\lambda}}\right)
$$

It is recommended to be used for the entire domain of turbulent flows, covering the whole range of Reynolds numbers and relative roughnesses. But there is a problem: this equation is implicit and must be solved by iterative methods. That was a major disadvantage and since the average engineer was not at all happy to apply numerical analysis techniques, the need for simple, explicit equations (to avoid $\mathrm{C}-\mathrm{W}$ ) was huge. As a result, over the years, the quest for $\mathrm{C}-\mathrm{W}$ alternatives was intense. Tradition played an important role, though. For example, traditionally Romanian hydraulics books [1],[2],[4] recommended Altshul's equation as an explicit, very simple way to compute the friction factor:

$$
\lambda=0.11 \cdot\left(k / D+\frac{68}{R e}\right)^{0.25}
$$

Is it the best solution? Why not investigate other alternatives?

During the last decades, many authors have proposed their own explicit equations, more or less complicated [5], trying to obtain good approximations for $\mathrm{C}-\mathrm{W}$ equation over the whole range of Reynolds numbers and relative roughnesses:

- $\quad$ Wood (1966) - for $4000<\operatorname{Re}<5 \cdot 10^{7}$ and $0.00001<\mathrm{k} / \mathrm{D}<0.04$

$\lambda=0.53 \cdot(k / D)+0.094 \cdot(k / D)^{0.225}+88 \cdot(k / D)^{0.44} \cdot \operatorname{Re}^{-1.62 \cdot(k / D)^{0.134}}$

- Swamee-Jain (1976) - for $5000<\operatorname{Re}<10^{8}$ and $0.000001<\mathrm{k} / \mathrm{D}<0.05$

$\lambda=\left[-2 \cdot \log _{10}\left(\frac{k / D}{3.7}+\frac{5.74}{\operatorname{Re}^{0.9}}\right)\right]^{-2}$

- $\quad$ Chen (1979) - for $4000<\operatorname{Re}<4 \cdot 10^{8}$

$\lambda=\left\{-2 \cdot \log _{10}\left[\frac{k / D}{3.7065}-\frac{5.0452}{R e} \cdot \log _{10}\left(\frac{(k / D)^{1.1098}}{2.8257}+\frac{5.8506}{R e^{0.8981}}\right)\right]\right\}^{-2}$

- Zigrang-Sylvester (1982) - for $4000<\mathrm{Re}<10^{8}$ and $0.00004<\mathrm{k} / \mathrm{D}<0.05$

$\lambda=\left\{-2 \cdot \log _{10}\left[\frac{k / D}{3.7}-\frac{5.02}{\operatorname{Re}} \cdot \log _{10}\left((k / D)-\frac{5.02}{\operatorname{Re}} \cdot \log _{10}\left(\frac{k / D}{3.7}+\frac{13}{\operatorname{Re}}\right)\right)\right]\right\}^{-2}$

- Haaland (1983) - for $4000<\operatorname{Re}<10^{8}$ and $0.000001<\mathrm{k} / \mathrm{D}<0.05$

$\lambda=\left\{-1.8 \cdot \log _{10}\left[\left(\frac{k / D}{3.7}\right)^{1.11}+\frac{6.9}{R e}\right]\right\}^{-2}$ 
- Manadilli (1997) - for $4000<\operatorname{Re}<10^{8}$ and $0<\mathrm{k} / \mathrm{D}<0.05$

$\lambda=\left[-2 \cdot \log _{10}\left(\frac{k / D}{3.7}+\frac{95}{R e^{0.983}}-\frac{96.82}{R e}\right)\right]^{-2}$

- Fang (2011) - for $3000<\operatorname{Re}<10^{8}$ and $0<\mathrm{k} / \mathrm{D}<0.05$

$\lambda=1.613 \cdot\left[\ln \left(0.234 \cdot(k / D)^{1.1007}-\frac{60.525}{R e^{1.1105}}+\frac{56.291}{R e^{1.0712}}\right)\right]^{-2}$

- Papaevangelou, Evangelides, Tzimopoulos (2010) [3] - for $4000<\operatorname{Re}<10^{8}$ and $0.000001<\mathrm{k} / \mathrm{D}<0.05$

$\lambda=\frac{0.2479-0.0000947 \cdot\left(7-\log _{10} R e\right)^{4}}{\left[\log _{10}\left(\frac{k / D}{3.615}+\frac{7.366}{R e^{0.9142}}\right)\right]^{2}}$

This selection is definitely not exhaustive, there are more complex and elaborated approaches, involving more than one equation, but promising better accuracy.

Many engineers are now facing a difficult choice and may ask themselves several questions about these alternatives:

-What is the degree of precision of these equations?

-Which is the most reliable?

-Why are so many alternatives needed?

-How difficult is to "invent" such a formula?

-Which equation works best for a Building Services engineer, in his real-life projects and hydraulic calculations?

\section{METHOD DESCRIPTION}

In order to answer all these questions, it is first necessary to investigate the entire set of equations, i.e. from (5) to (13) in comparison with (4), over the whole range of Reynolds numbers and relative roughnesses.

The relative error $\delta$ of all these approximate formulas with respect to the $\mathrm{C}-\mathrm{W}$ equation will be calculated as follows:

$$
\delta=\frac{\lambda_{\mathrm{C}-\mathrm{W}}-\lambda}{\lambda_{\mathrm{C}-\mathrm{W}}} \cdot 100 \quad[\%]
$$

A total number of 645 testing points were used, generated by 15 relative roughness values combined with 43 Reynolds numbers (presented separately in Table 1 and Table 2), covering a range $4000<\operatorname{Re}<10^{8}$ and $0.000001<\mathrm{k} / \mathrm{D}<0.05$ :

Table 1. Relative roughness values used to check the accuracy of various equations

\begin{tabular}{|l|l|l|l|l|}
\hline 0.000001 & 0.00001 & 0.0001 & 0.001 & 0.01 \\
\hline 0.000003 & 0.00003 & 0.0003 & 0.003 & 0.03 \\
\hline 0.000007 & 0.00007 & 0.0007 & 0.007 & 0.05 \\
\hline
\end{tabular}


Table 2. Reynolds number values used to check the accuracy of various equations

\begin{tabular}{|l|l|l|r|r|r|}
\cline { 2 - 5 } \multicolumn{1}{c|}{} & 10000 & 100000 & 1000000 & 10000000 & 100000000 \\
\cline { 2 - 5 } \multicolumn{1}{c|}{} & 20000 & 200000 & 2000000 & 20000000 & \multirow{2}{*}{} \\
\cline { 2 - 5 } \multicolumn{1}{c|}{30000} & 300000 & 3000000 & 30000000 \\
\hline 4000 & 40000 & 400000 & 4000000 & 40000000 \\
\hline 5000 & 50000 & 500000 & 5000000 & 50000000 \\
\hline 7000 & 60000 & 600000 & 6000000 & 60000000 \\
\hline 8000 & 70000 & 700000 & 7000000 & 70000000 \\
\hline 9000 & 90000 & 800000 & 8000000 & 80000000 \\
\hline
\end{tabular}

For each of these 645 testing points, a $\lambda$ value was calculated following each of the 9 equations in discussion, then the relative error to $\mathrm{C}-\mathrm{W}$ formula was determined, using (14).

A MS Excel spreadsheet was used in order to make all the friction factor calculations, comparisons and finally draw the conclusions. The implicit $\mathrm{C}-\mathrm{W}$ equation was solved using the Newton-Raphson numerical method, implemented into a dedicated Visual Basic for Applications macro.

\section{RESULTS AND SIGNIFICANCES}

\subsection{Main comparison}

The obtained results are very interesting and are subject to raise more questions and investigation. Table 3 shows the results in a concise form, based on maximum (positive and negative) relative error for the 9 explicit approximations of the $\mathrm{C}-\mathrm{W}$ equation.

Table 3. Maximum (+/-) relative error for the 9 explicit equations compared to the $\mathrm{C}-\mathrm{W}$ formula in 645 points

\begin{tabular}{|l|c|c|}
\hline $\begin{array}{c}\text { Number/name } \\
\text { of the explicit equation }\end{array}$ & $\begin{array}{c}\text { Max. positive } \\
\text { relative error } \\
\text { [\%] }\end{array}$ & $\begin{array}{c}\text { Max. negative } \\
\text { relative error } \\
\text { [\%] }\end{array}$ \\
\hline (5) Altshul & 38.424 & -2.673 \\
\hline (6) Wood & 28.234 & -6.241 \\
\hline (7) Swamee-Jain & 0.703 & -3.412 \\
\hline (8) Chen & 0.315 & -0.360 \\
\hline (9) Zigrang-Sylvester & 3.189 & -0.125 \\
\hline (10) Haaland & 1.403 & -1.291 \\
\hline (11) Manadilli & - & -2.812 \\
\hline (12) Fang & 0.411 & -0.600 \\
\hline (13) Papaevangelou et al. & 0.697 & -0.616 \\
\hline
\end{tabular}

It can be seen that Altshul and Wood equations have obtained poor results and can be eliminated from the competition.

Chen has surprisingly good results for such an old equation, Fang is performing excellent too, Manadilli is constantly overestimating $\mathrm{C}-\mathrm{W}$ (the relative error is never positive) and finally, Haaland is not too bad for such a simple equation.

The winner seems to be (8) Chen, at least based on the 645 testing points... 
Is this verdict rock solid?

Not really, because it seems that each equation has a "weak spot" where unexpected things can happen, i.e. locally the relative error can present a dangerous spike, even though in the rest of the range the results remain good. Relative error interpretation shows that these abnormal regions are found for some equations at low Re and small k/D values, but for others in the middle ranges, so there is no general rule to follow.

\subsection{Testing some real-life hydraulic calculations for Building Services projects}

As mentioned before, for a Building Services engineer it is important to know what equation will give the best results in the case of the usual, daily-basis pipe hydraulic calculations.

In order to select the best equation, several scenarios were investigated:

a) Copper pipe, small diameters ranging from $10 \times 1$ to $267 \times 3 \mathrm{~mm}$, cold water, fluid velocity of $0.7 \mathrm{~m} / \mathrm{s}$ (Table 4)

Table 4. Maximum (+/-) relative error for the 9 explicit equations compared to the $\mathrm{C}-\mathrm{W}$ formula -scenario a)

\begin{tabular}{|l|c|c|}
\hline $\begin{array}{c}\text { Number/name } \\
\text { of the explicit equation }\end{array}$ & $\begin{array}{c}\text { Max. positive } \\
\text { relative error } \\
{[\%]}\end{array}$ & $\begin{array}{c}\text { Max. negative } \\
\text { relative error } \\
{[\%]}\end{array}$ \\
\hline (5) Altshul & 2.506 & -2.514 \\
\hline 6) Wood & 2.054 & -1.514 \\
\hline (7) Swamee-Jain & 0.598 & -1.697 \\
\hline (8) Chen & 0.179 & -0.153 \\
\hline (9) Zigrang-Sylvester & 0.752 & - \\
\hline (10) Haaland & 1.121 & -0.755 \\
\hline (11) Manadilli & - & -0.276 \\
\hline (12) Fang & 0.114 & -0.117 \\
\hline (13) Papaevangelou et al. & 0.107 & -0.226 \\
\hline
\end{tabular}

It seems that Altshul and Wood are still performing bad and take last places, but their performance is technically acceptable if we consider a 5\% relative error in Building Services Engineering design projects as common.

Fang is the winner here, closely followed by Chen and Papaevangelou et al.

Zigrang-Sylvester is constantly underestimating $\mathrm{C}-\mathrm{W}$ in this situation.

b) Copper pipe, small diameters ranging from $10 \times 1$ to $267 \times 3 \mathrm{~mm}$, cold water, fluid velocity of $2 \mathrm{~m} / \mathrm{s}$ (Table 5)

Changing only water velocity from the previous case is quickly affecting the results: the winner is (13).

Chen and Manadilli are overestimating, while Haaland and Fang are underestimating C-W by a small margin. Altshul is going worse than before, but Wood has better results. 
Table 5. Maximum (+/-) relative error for the 9 explicit equations compared to the $\mathrm{C}-\mathrm{W}$ formula - scenario b)

\begin{tabular}{|l|c|c|}
\hline $\begin{array}{c}\text { Number/name } \\
\text { of the explicit equation }\end{array}$ & $\begin{array}{c}\text { Max. positive } \\
\text { relative error } \\
{[\%]}\end{array}$ & $\begin{array}{c}\text { Max. negative } \\
\text { relative error } \\
\text { [\%] }\end{array}$ \\
\hline (5) Altshul & 7.476 & -2.201 \\
\hline (6) Wood & 1.169 & -0.077 \\
\hline (7) Swamee-Jain & 0.426 & -0.579 \\
\hline (8) Chen & - & -0.223 \\
\hline (9) Zigrang-Sylvester & 1.187 & 0.473 \\
\hline (10) Haaland & 1.295 & - \\
\hline (11) Manadilli & - & -0.493 \\
\hline (12) Fang & 0.213 & - \\
\hline (13) Papaevangelou et al. & 0.062 & -0.154 \\
\hline
\end{tabular}

c) Glassfiber reinforced plastic (GRP) pipe, big diameters ranging from $168 x 6$ to $2555 \times 57 \mathrm{~mm}$, cold water, fluid velocity of $1 \mathrm{~m} / \mathrm{s}$ (Table 6)

Table 6. Maximum (+/-) relative error for the 9 explicit equations compared to the $\mathrm{C}-\mathrm{W}$ formula - scenario c)

\begin{tabular}{|l|c|c|}
\hline $\begin{array}{c}\text { Number/name } \\
\text { of the explicit equation }\end{array}$ & $\begin{array}{c}\text { Max. positive } \\
\text { relative error } \\
{[\%]}\end{array}$ & $\begin{array}{c}\text { Max. negative } \\
\text { relative error } \\
{[\%]}\end{array}$ \\
\hline (5) Altshul & 16.857 & - \\
\hline (6) Wood & 1.984 & -0.860 \\
\hline (7) Swamee-Jain & 0.294 & -0.053 \\
\hline (8) Chen & - & -0.232 \\
\hline (9) Zigrang-Sylvester & 0.832 & - \\
\hline (10) Haaland & 1.356 & - \\
\hline (11) Manadilli & - & -0.349 \\
\hline (12) Fang & 0.207 & - \\
\hline (13) Papaevangelou et al. & 0.048 & -0.097 \\
\hline
\end{tabular}

Modifying pipe material and going to big diameters in water distribution networks brought some rank changes: Papaevangelou et al. is the absolute leader now, followed by Fang and Chen, then Swamee-Jain and Manadilli. Zigrang-Sylvester, Haaland and Wood are still good below $2 \%$, but Altshul is performing unexpectedly bad.

d) Glassfiber reinforced plastic (GRP) pipe, big diameters ranging from $168 x 6$ to $2555 \times 57 \mathrm{~mm}$, cold water, fluid velocity of $4 \mathrm{~m} / \mathrm{s}$ (Table 7)

Table 7. Maximum (+/-) relative error for the 9 explicit equations compared to the C-W formula - scenario d)

\begin{tabular}{|l|c|c|}
\hline $\begin{array}{c}\text { Number/name } \\
\text { of the explicit equation }\end{array}$ & $\begin{array}{c}\text { Max. positive } \\
\text { relative error } \\
\text { [\%] }\end{array}$ & $\begin{array}{c}\text { Max. negative } \\
\text { relative error } \\
\text { [\%] }\end{array}$ \\
\hline (5) Altshul & 22.991 & - \\
\hline (6) Wood & - & -4.129 \\
\hline
\end{tabular}




\begin{tabular}{|l|c|c|}
\hline (7) Swamee-Jain & - & -0.613 \\
\hline (8) Chen & - & -0.309 \\
\hline (9) Zigrang-Sylvester & 0.969 & - \\
\hline (10) Haaland & 1.147 & - \\
\hline (11) Manadilli & - & -0.637 \\
\hline (12) Fang & 0.366 & - \\
\hline (13) Papaevangelou et al. & - & -0.326 \\
\hline
\end{tabular}

This time the results are providing two different sets of equations: the underestimating set, where the leader is Fang, and the overestimating set, where the leader is Chen, closely followed by (13). Both sets give very good results, excepting Wood and Altshul. Altshul performs very badly and is clearly the last again.

\subsection{Is the quest over?}

No, not at all. It seems that the appetite for discovering new formulas is still present.

So, after all, how difficult can be to propose a new explicit equation as a viable alternative to $\mathrm{C}-\mathrm{W}$ ?

From a mathematical point of view, it is necessary to find a function of two independent variables, applying a nonlinear regression over a very large number of points, in order to increase precision. In fact, the friction factor equation spatially represents a surface covering the entire range of $\mathrm{Re}$ and $\mathrm{k} / \mathrm{D}$ values. Therefore, having available 645 testing points, why not use a software to perform the two variable nonlinear regression?

The good news is that nowadays such software is freely available. And sometimes even online, for example at zunzun.com. This site offers surface fitting for 3D data, with a rich set of statistics and plots, generating PDF file output and even source code in various programming languages.

After loading all the $6453 \mathrm{D}$ points as an ASCII file, the pyeq3 genetic algorithm behind the Python-powered site suggested the following best fitting formula (a Polyfunctional), with a correlation coefficient of 0.99132 :

$$
\lambda=a \cdot\left(\ln (R e)^{-2}\right)+b \cdot(\sqrt{k / D} \cdot \ln (R e))
$$

where $a=2.4573190804602487 \mathrm{E}+00$ and $b=1.7806050776768417 \mathrm{E}-02$.

But the joy was short-lived when the relative error plot was examined (Fig. 1), as extreme $+20 \%$ and $-13 \%$ relative errors are not acceptable. It may be noticed that a huge cloud of $\delta$ points is situated outside the $\pm 5 \%$ limits; therefore this equation is not a winner. 


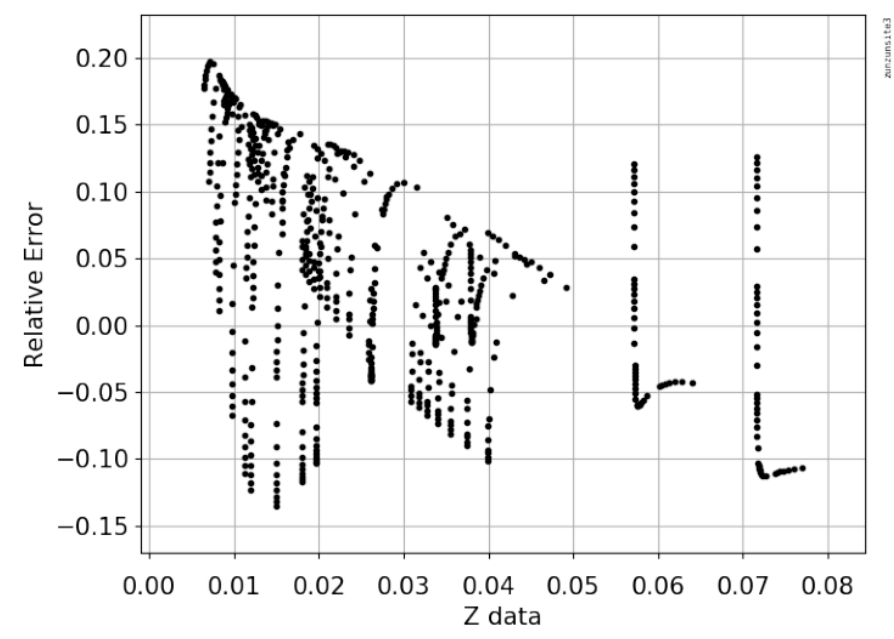

Fig. 1. Relative error distribution for the best ranked by ZunZun fitting equation

If the automatic Function Finder is not able to find something better from the existing database of implemented equations, it is possible to try a user-defined equation. This is a tempting option, so the next attempt was to propose the finding of an equation with a structure very close to Haaland's:

$$
\lambda=\left\{a \cdot \log _{10}\left[\left(\frac{k / D}{3.7}\right)^{1.11}+\frac{b}{\operatorname{Re}}\right]\right\}^{-2}
$$

where the calculated constants (by ZunZun) were $a=1.8013979695915863 \mathrm{E}+00$ and $b=6.9374584478235786 \mathrm{E}+00$, which are very close to the "original" values from (10).

The correlation coefficient is a very good one, 0.9999707 and the relative error distribution is consistent with the values from Table 3 .

\section{CONCLUSIONS}

This paper is making an overview of the most used alternatives to the ColebrookWhite equation, analyzing their mathematical accuracy along the whole range of Reynolds numbers and relative roughnesses. Testing these equations within the framework of some specific Building Services hydraulic calculations demonstrated that there is no absolute "winner" for all scenarios. The good news is that all explicit equations performed quite well, with the exception of Altshul's, which was a real dissapointment and should be avoided (despite the tradition). Wood's behaviour was not at all remarkable, either.

While the discussed scenarios are by no means exhaustive, these results may however be used by Building Services engineers as guidance if they want to avoid iterative calculations.

Furthermore, it was demonstrated that using the latest available free software tools, an engineer can invent or propose an empirical explicit equation based on a sufficient large 
number of points. However, those "out of the hat" equations should be carefully checked and fine-tuned in order to have a chance to challenge the "classics" in terms of precision.

Well-preparing a user-defined function may bring some new and precise equations in the future, so the quest is still on.

\section{REFERENCES}

[1] Florea J., Seteanu I., Zidaru Gh., Panaitescu V. (1982), Mecanica fluidelor şi maşini hidropneumatice, Editura Didactică şi Pedagogică, Bucureşti.

[2] Isbăşoiu E. C. Gh., Georgescu S.-C. (1995), Mecanica fluidelor, Editura Tehnică, Bucureşti.

[3] Papaevangelou G., Evangelides C., Tzimopoulos C. (2010), A new explicit relation for the friction coefficient in the Darcy-Weisbach equation. In: Protection and Restoration of the Environment X, University of Ioannina (Greece) \& Stevens Institute of Technology (New Jersey), Corfu, Greece, pp. 1-7.

[4] Popescu F., Paraschiv L.S., Paraschiv S., Frătița M., Alexandru I. (2018), Mecanica fluidelor - Indrumar de laborator, Editura Fundaţiei Universitare "Dunărea de Jos" din Galaţi.

[5] S. Genić, I. Arandjelović, P. Kolendić, M. Jarić, N. Budimir, V. Genić (2011), A Review of Explicit Approximations of Colebrook's Equation, FME Transactions, vol. 39, pp. 67-71, Belgrade, Serbia.

\section{Note:}

Bacoțiu Ciprian - Technical University of Cluj-Napoca, Strada Memorandumului 28, 400114 ClujNapoca, Romania (corresponding author phone: +40-264-202557; fax: +40-264-410179; e-mail: ciprian.bacotiu@insta.utcluj.ro). 